\title{
Takotsubo cardiomyopathy in peripartum period: a case report
}

\section{Chitramani Sundararajan $^{1 *}$, Thamizh naveena ${ }^{1}$, Priya Kubendiran ${ }^{2}$}

\author{
${ }^{1}$ Department of Obstetrics and Gynecology, ${ }^{2}$ Department of Cardiology, GKNM Hospital, Coimbatore, Tamil Nadu, \\ India
}

Received: 24 October 2021

Revised: 14 November 2021

Accepted: 15 November 2021

\section{*Correspondence:}

Dr. Chitramani Sundararajan,

E-mail: dr_chitramani@yahoo.com

Copyright: (c) the author(s), publisher and licensee Medip Academy. This is an open-access article distributed under the terms of the Creative Commons Attribution Non-Commercial License, which permits unrestricted non-commercial use, distribution, and reproduction in any medium, provided the original work is properly cited.

\begin{abstract}
Cardiomyopathy is a group of disorders characterised by structural and functional abnormalities in the myocardium in the absence of other cardiac diseases of myocardial abnormality. Its occurrence in pregnancy is uncommon and exact incidence is unknown even though some studies shows that the incidence of peripartum cardiomyopathy is 1 in 1000 to 4000 births. Here we have discussed about a 34 years primigravida with twin pregnancy conceived after 12 years of married life by assisted reproductive technique (ART), admitted with preterm premature rupture of membranes (PPROM) at 28 weeks of gestation who developed a rare condition called Takotsubo cardiomyopathy (TC) in the peripartum period. She was managed in intensive care unit with oxygen supplementation, beta blockers, diuretics and heparin. Patient had an excellent recovery in the early postoperative period.
\end{abstract}

Keywords: Takotsubo cardiomyopathy, Pregnancy, Peripartum cardiomyopathy

\section{INTRODUCTION}

Cardiomyopathies in pregnancy are relatively rare diseases, of which takotsubo cardiomyopathy is an uncommon type seen usually in the peripartum period. It is a clinical syndrome characterised by an acute and transient (21 days) left ventricular systolic (and diastolic) dysfunction often related to an emotional or physical stressful event, most often identified in the preceding days ( 1 to 5 days). ${ }^{1-4}$ It is a cardiac emergency and a diagnosis of exclusion. ${ }^{1}$ Takotsubo cardiomyopathy was originally described in Japan in 1990s. ${ }^{2}$ Tako-means octopus and tsubo-means jar which was used to trap octopus, a unique short neck round flask shaped form of left ventricular apical ballooning. ${ }^{3} \mathrm{TC}$ is also known with many other names such as apical ballooning syndrome, broken heart syndrome and stress cardiomyopathy. ${ }^{4,5}$

Takotsubo cardiomyopathy is often precipitated by intense emotional or physical stress. ${ }^{6}$ Women are more affected than men and usually in postmenopausal state and not so commonly seen in pregnant population. ${ }^{1,7-9}$ During pregnancy it is usually prevalent in women with some high risk factors like age $>35$ years, multiple gestation, preterm birth, tocolytics, caesarean section (CS), postpartum haemorrhage and use of uterotonics. ${ }^{3,8}$ Ionotropes and/or vasopressors were also known to be precipitating factors for developing TC. ${ }^{10}$ The case which we have reported here had multiple risk factors which are mentioned here like emotional and physical stress, multiple gestation, preterm, operative delivery, use of uterotonics.

\section{CASE REPORT}

A 34-year-old, primigravida, married since 12 years, conceived by ART with dichorionic diamniotic twins at 28 weeks of gestation, known hypothyroid (thyroid function tests were normal with medication) was referred for tertiary care in view of PPROM. On admission, she was afebrile, pulse rate (PR) 92/min, blood pressure (BP) $120 / 80 \mathrm{mmHg}$, oxygen saturation $(\mathrm{SpO} 2) 100 \%$ in room 
air. Cardiovascular and respiratory systems examination were normal. She was not in labour. Heart rates for both foetuses were normal. No clinical/laboratory evidence of chorioamnionitis. Prophylactic steroids for fetal lung maturity and antibiotics were administered. Ultrasound scan revealed 1 st twin anhydramnios with cord presentation. CS was planned for the next day after detailed informed consent.

Following the decision for delivery, her PR started to slowly rise throughout the night ranging from 100120 /min. She had no cardio-respiratory complaints. Prior to administration of spinal anaesthesia, her PR was 130140/min with normal sinus rhythm. Both babies were delivered by $\mathrm{CS}$ and admitted in neonatal intensive care unit for preterm care. Inj. oxytocin 10 units intravenous (IV) was administered. She had uterine atonicity which was controlled with IV methergin $0.2 \mathrm{mg}$ and rectal misoprostol $600 \mathrm{mg}$.

Intra operatively after 10 minutes of delivery, she complained of severe headache, breathlessness and giddiness. She had transient elevation of BP (195/120 $\mathrm{mmHg}$ ), with PR 150/min and SpO2 $100 \%$. Electrocardiography (ECG) showed transient broad QRS complex lasting for few seconds suggestive of paroxysmal ventricular tachycardia. Injection midazolam $2 \mathrm{mg}$ IV was administered. Her BP gradually reduced to $90 / 60 \mathrm{mmHg}$, PR was $100 / \mathrm{min}, \mathrm{SpO} 2$ was $100 \%$ with 5 lit $\mathrm{O} 2$. Her complaints had improved.

In the immediate post-operative period, cardiology opinion was sought. Her vitals were BP 150/100 mmHg, PR was112/min, SpO2 was 98 with 5lit O2. She had bilateral basal inspiratory crepitations. Cardiovascular examination was clinically normal. ECG (Figure 1) showed sinus rhythm 110/min with qR in lead aVL and no other significant ST-T changes. Bedside chest $\mathrm{X}$-ray (Figure 2) revealed cardiomegaly with grade 1 pulmonary venous hypertension.

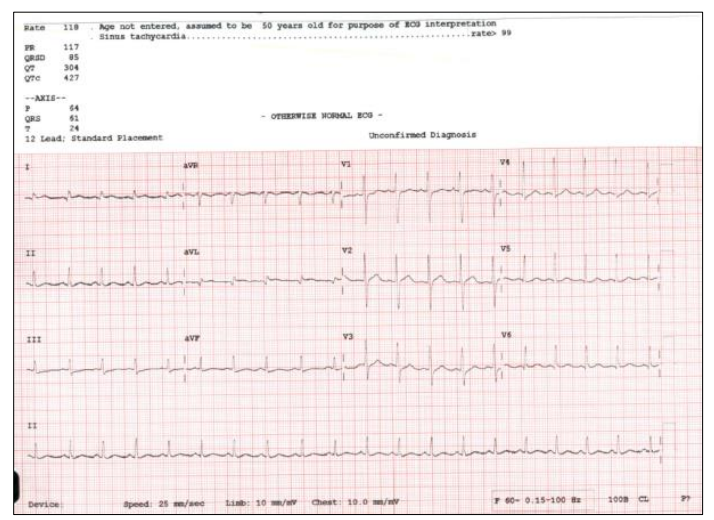

Figure 1: ECG findings in immediate postoperative period.

Bedside 2D Echo showed global hypokinesia with severe left ventricular (LV) dysfunction with ejection fraction
(EF) $\sim 30 \%$. There was no evidence of pulmonary artery hypertension, right atrial or right ventricular dilatation to suggest pulmonary thromboembolism. She was treated with oral beta blocker (metaprolol) and IV diuretics (furosemide). Blood investigations revealed elevated cardiac biomarkers (hs-troponin I 1948). Subcutaneous unfractionated heparin and tablet aspirin were started. She remained clinically stable. 6 hours later, PR was $112 / \mathrm{min}, \mathrm{BP}$ was $130 / 60 \mathrm{mmHg}, \mathrm{SpO} 2$ was $98 \%$ with $5 \mathrm{~L}$ $\mathrm{O} 2$. Follow up ECG (Figure 3) showed new changes of T wave inversion in leads $\mathrm{V} 1, \mathrm{~V} 2$.

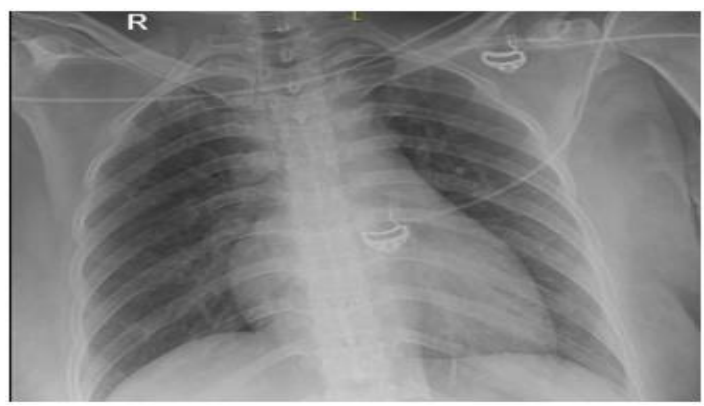

Figure 2: Bedside chest X-ray PA view in immediate postoperative period showing cardiomegaly.

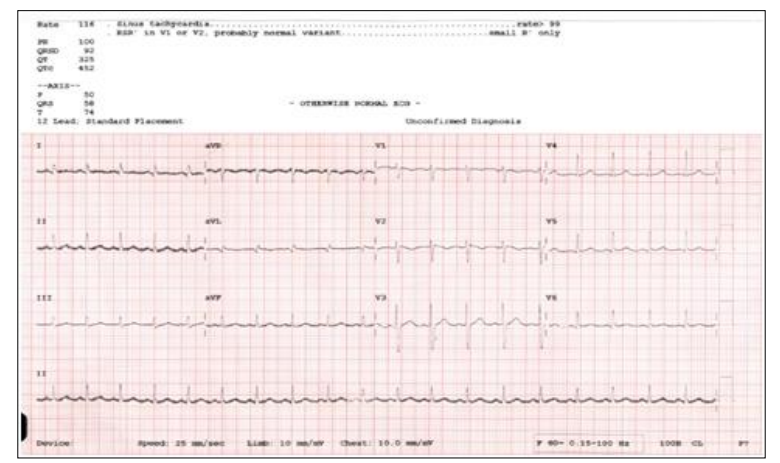

Figure 3: ECG findings 6 hours post caesarean section.

Bedside 2D Echo showed global hypokinesia more in apical and mid segments, moderate LV dysfunction (EF $40 \%$ ), mild to moderate MR. Takotsubo cardiomyopathy was suspected. Beta blockers, diuretics, heparin were continued. 12 hours later, repeat hs troponin I dropped to 719. As patient condition improved, she was transferred from intensive care unit to the ward on postoperative day 2. 2D Echo was repeated on postoperative day 2. It showed mild global hypokinesia with improvement in LV function with ejection fraction of $50 \%$. She was confirmed to have Takotsubo cardiomyopathy as per clinical, laboratory and echo findings. Coronary angiogram was not done in view of young age, as she had no other significant cardiac risk factors. Patient was discharged on postoperative day 7. She was continued on beta blockers along with heparin. Echo on postoperative day 11 was normal with normal LV function with ejection fraction of $63 \%$. At 6 weeks of her postnatal visit, her cardiac condition was stable with beta blocker. 


\section{DISCUSSION}

The exact cause of takotsubo cardiomyopathy is not known. ${ }^{6}$ However, proposed pathophysiological mechanisms include transient coronary artery spasm, catecholamine excess, microvascular dysfunction triggered by an unclear mechanism. ${ }^{4}$ Hypo or akinesia usually occurs in apical segment of left ventricle in majority of the cases and uncommonly in midsegment or basal segments. When it occurs in basal segment of the left ventricle, it is termed as reverse takotsubo cardiomyopathy. ${ }^{11,12}$ Patients usually present with chest pain and/or breathlessness and it can occur even during the time of caesarean as in this patient who became symptomatic on operative table. This patient was very apprehensive due to much awaited pregnancy conceived after 12 years of married life and also due to unexpected very early rupture of membranes with the necessity of urgent preterm delivery. Takotsubo cardiomyopathy is associated with in-hospital mortality of $2 \%$, in-hospital complication rate of $19 \%$ like heart failure, arrhythmias, thrombus formation etc. ${ }^{4}$ Its recurrence rate is up to $5 \% .{ }^{4}$ Patients with TC have a good prognosis as they recover soon after delivery within days to 3 months. ${ }^{13}$ Diagnosis of TC is made using Heart Failure Association- European Society of Cardiology Criteria (Table 1). ${ }^{14}$

\section{Table 1: Heart failure association-European society of cardiology criteria. ${ }^{14}$}

\section{Criteria}

Transient regional wall motion abnormalities of left ventricle or right ventricle myocardium, which are frequently, but not always, preceded by a stressful trigger (emotional or physical).

The regional wall motion abnormalities usually extend beyond a single epicardial vascular distribution, and often result in circumferential dysfunction of the ventricular segments involved.

The absence of culprit atherosclerotic coronary artery disease, including acute plaque rupture, thrombus formation, and coronary dissection or other pathological conditions to explain the pattern of temporary LV dysfunction observed (e.g., hypertrophic cardiomyopathy, viral myocarditis).

New and reversible electrocardiography abnormalities (ST-segment elevation, ST-segment depression, Left bundle branch block, T-wave inversion, and/or QTc prolongation) during the acute phase (3 months). Significantly elevated serum natriuretic peptide (BNP or NT-proBNP) during the acute phase.

Positive but relatively small elevation in cardiac troponin measured with conventional assay (i.e., disparity between the troponin level and the amount of dysfunctional myocardium present).

Recovery of ventricular systolic function on cardiac imaging at follow-up (3 to 6 months).
Bedside 2D echocardiography remains the first line diagnostic tool applied along with clinical examination, ECG and troponin levels. ${ }^{2}$ Differential diagnosis includes acute coronary syndrome, pulmonary embolism, peripartum cardiomyopathy and myocarditis. ${ }^{5}$ Timing and mode of delivery should be based on obstetrical factors. ${ }^{1}$ There has been a case report of patient developing TC in mid-trimester, managed and delivered at term. ${ }^{15} \mathrm{~A}$ multidisciplinary team approach is essential in managing these patients comprising cardiologist, obstetrician, neonatologist and anesthetist. ${ }^{13}$

Vasoconstricting agents like ergot alkaloids like methergine, bromocryptine are better avoided when TC is suspected. ${ }^{16}$ Here patient received methergine intraoperatively due to atonicity as TC was suspected only in postoperative period. Cardiac management is usually beta blockers, aspirin, hydralazine, nitrates, diuretics and anticoagulation. ${ }^{17}$ Angiotensin converting enzyme inhibitors can be given only after delivery of the fetus. ${ }^{17}$

\section{CONCLUSION}

Takotsubo cardiomyopathy is a rare type seen in pregnant women. It is an acute cardiac emergency warranting prompt diagnosis and immediate care in intensive care setup with multidisciplinary team. When compared to peripartum cardiomyopathy, its recovery period to normal cardiac function is much earlier with Takotsubo cardiomyopathy. However, a close follow up is required after discharge to detect any major adverse cardiac and cerebrovascular events and also during subsequent pregnancy.

\section{Funding: No funding sources \\ Conflict of interest: None declared \\ Ethical approval: Not required}

\section{REFERENCES}

1. Oindi FM, Sequeira E, Sequeira HR, Mutiso SK. Takotsubo cardiomyopathy in pregnancy: A case report and literature review. BMC Preg Childbirth. 2019;19(1):1-6.

2. Minatoguchi M, Itakura A, Takagi E, Nishibayashi M, Kikuchi M, Ishihara O. Takotsubo cardiomyopathy after cesarean: A case report and published work review of pregnancy-related cases. J Obstet Gynaecol Res. 2014;40(6):1534-9.

3. Shoji T, Takatori E, Oyama R, Kumagai S, Fukushima A, Yoshizaki A, et al. Tako-tsubo cardiomyopathy caused immediately following cesarean section delivery of triplets: A case report. Gynecol Obstet Invest. 2012;74(1):84-8.

4. Rao BVN, Rekha A, Narayan AS, Manjusha A. Takotsubo cardiomyopathy complicating a twin pregnancy at partum. Int J Res Med Sci. 2019;7(11): 4375.

5. Ruiz S, Martinez-Marin M, Luque P, Nassar N, Oros 
D. Takotsubo cardiomyopathy after cesarean section: A case report and literature review. J Obstet Gynaecol Res. 2017;43(2):392-6.

6. Vujin B, Kovačević D, Petrović M, Ivanov I, Panić G. Takotsubo cardiomyopathy in pregnancy. Cent Eur $\mathrm{J}$ Med. 2014;9(1):49-53.

7. Sato A, Yagihara N, Kodama M, Mitsuma W, Tachikawa H, Ito M, et al. Takotsubo cardiomyopathy after delivery in an oestrogen-deficient patient. Int $\mathbf{J}$ Cardiol. 2011;149(2):78-9.

8. Rodolfo Citro, MD P, Alexander Lyon, MD P, Eloisa Arbustini M, Eduardo Bossone, MD P, Federico Piscione M, Christian Templin, MD P, et al. Takotsubo Syndrome After Cesarean Section. Cent Eur J Med. 2021;71(16):0-1.

9. Bhattacharyya PJ, Attri PK, Farooqui W. Takotsubo cardiomyopathy in early term pregnancy: A rare cardiac complication of SARS-CoV-2 infection. BMJ Case Rep. 2020;13(9):1-2.

10.Kucia AM, Dekker G, Arstall M. Peripartum Takotsubo Cardiomyopathy. J Am Coll Cardiol. 2015;65(10): A926.

11.Kilian L, Haaf P, Pfister O, Vischer AS, Lapaire O, Burkard T. Reverse Takotsubo syndrome, a case report of a rare cause for postpartum heart failure. Cardiogenetics. 2018;8(1):13-6.

12.Kourkoveli P, Leontiadis E, Kontonika M, Antoniou T, Iakovou I, Karatasakis G. Reverse Takotsubo Cardiomyopathy After Caesarean Section with Epidural Anesthesia: Initial Assessment and Followup. J Cardiothoracic Vasc Anesth. 2020;34(3):756-8.
13.Schaufelberger M. Cardiomyopathy and pregnancy. Heart. 2019;105(20):1543-51.

14.Horacio MC, Marco GDB, Lori K-M, Liangsuo M.F. Gerard M, Daniel B, Antonio A. Stress Cardiomyopathy Diagnosis and Treatment. J Am Coll Cardiol. 2018;72:1955-71.

15.American College of Cardiology. Peripartum Takotsubo Cardiomyopathy. Am Coll Cardiol. 2021; 7(2016):6.

16.Enderton EL, Cardwell MS. Postpartum takotsubo cardiomyopathy with reversible cerebral vasoconstriction syndrome: a case report. Case Reports Perinat Med. 2013;2(1-2):21-4.

17.Brezina P, Isler CM. Takotsubo cardiomyopathy in pregnancy. Obstet Gynecol. 2008;112(2):450-2.

18.Kim DY, Kim SR, Park SJ, Seo JH, Kim EK, Yang $\mathrm{JH}$, et al. Clinical characteristics and long-term outcomes of peripartum takotsubo cardiomyopathy and peripartum cardiomyopathy. ESC Hear Fail. 2020;7(6):3644-52.

19.Yang WI, Moon JY, Shim M, Yang PS, Kang SH, Kim SH, et al. Clinical features differentiating Takotsubo cardiomyopathy in the peripartum period from peripartum cardiomyopathy. Heart Vessels. 2020;35(5):665-71.

Cite this article as: Sundararajan C, Naveena T, Kubendiran P. Takotsubo cardiomyopathy in peripartum period: a case report. Int J Reprod Contracept Obstet Gynecol 2021;10:4566-9. 